\title{
SHARPS INJURIES AMONG MEDICAL STUDENTS IN THE FACULTY OF MEDICINE, COLOMBO, SRI LANKA
}

\section{ISURUJITH K LIYANAGE ${ }^{1}$, TSKRD CALDERA ${ }^{1}$, RAJAPAKSHA RWMA ${ }^{2}$, CK LIYANGE ${ }^{4}$, PUBUDU DE SILVA ${ }^{3}$, and IM KARUNATHILAKE ${ }^{4}$}

${ }^{1}$ General Sir John Kotelawala Defence University, Colombo, Sri Lanka

Faculty of Medicine

${ }^{2}$ Peradeniya Teaching Hospital, Peradeniya, Sri Lanka

${ }^{3}$ Ministry of Health, Colombo, Sri Lanka

${ }^{4}$ University of Colombo, Colombo, Sri Lanka

Medical Education Development and Research Center, Faculty of Medicine

\begin{abstract}
Introduction: Medical students undertake clinical procedures which carry a risk of sharps injuries exposing them to bloodborne infections. Objectives: To study the prevalence and correlates of sharps injuries among 4th-year medical students in the Faculty of Medicine, University of Colombo, Sri Lanka. Materials and Methods: The survey was conducted among 4th-year medical students to find out the incidence of injuries during high-risk procedures, associated factors and practice and perceptions regarding standard precautions. A self-administered questionnaire was administered to a batch of 197 4th-year medical students. Results: A total of 168 medical students responded. One or more injury was experienced by $95 \%(\mathrm{~N}=159)$ of the students. The majority $(89 \%)$ occurred during suturing; $23 \%$ during venipuncture and $14 \%$ while assisting in deliveries. Most of the incidents (49\%) occurred during Obstetrics and Gynecology attachments. Recapping needles led to $8.6 \%$ of the injuries. Thirty-five percent of students believed they were inadequately protected. In this group, adequate protection was not available in $21 \%$ of the incidences and $24 \%$ thought protection was not needed. Following the injury, $47 \%$ completely ignored the event and only $5.7 \%$ followed the accepted post-exposure management. Only $34 \%$ of the students knew about post-exposure management at the time of the incident. Only $15 \%$ stated that their knowledge regarding prevention and management was adequate. The majority (97\%) believed that curriculum should put more emphasis on improving the knowledge and practice regarding sharps injuries. Conclusions: The incidence of sharps injuries was high in this setting. Safer methods of suturing should be taught and practiced. The practice of standard precautions and post-injury management should be taught.
\end{abstract}

Key words:

Sharps injury, Medical students occupational safety, Needle-stick injuries

\section{INTRODUCTION}

Health care workers $(\mathrm{HCW})$ are constantly exposed to contaminated sharps instruments. This exposes them to various blood-borne infections (BBIs) including HIV, Hepatitis B and Hepatitis C and many other pathogens [1-3].
The estimated population prevalence of HIV/AIDS was less than $0.1 \%$ in Sri Lanka [4]. However, the current social structure in Sri Lanka and its proximity to India which has a large population with HIV/AIDS [5,6] places Sri Lanka at a highly vulnerable state for a large epidemic of HIV/AIDS [7]. In addition, there is paucity of data on

Received: June 26, 2011. Accepted: April 3, 2012.

Address reprint request to I.K. Liyanage, Faculty of Medicine, General Sir John Kotelawala Defence University, Kandawala Watta, Ratmalana, Sri Lanka (e-mail: isurujith@gmail.com). 
the prevalence of other blood-borne diseases such as hepatitis viruses among the Sri Lankan population. Therefore, reducing the number of incidences that carry a high risk of transmitting BBIs is important for health care workers.

HCWs in low- and medium-income countries (LMCs), including Sri Lanka, are involved in a larger number of invasive procedures than their counterparts of the same capacity from developed countries. Overworked health care workers are more likely to sustain sharps injuries. Therefore, HCWs from LMCs are at a higher risk of sustaining sharps injuries. This increases the high risk exposure. In addition, HCWs tend to develop unsafe practices in developing countries [8]. Many observers have noted an unsatisfactory standards in the practice of precautions and correct post exposure practices in many centers [9].

Medical students are involved in hands-on training concerning many invasive procedures. These involve giving intravenous injections, drawing blood, intravenous cannulation, assisting in theaters and labor rooms. This is a vulnerable period to sustain sharps injuries [10] especially since the lack of experience is a known risk factor for sharps injuries [11,12]. This is also the time when they obtain the skills to carry out the procedures correctly and to protect themselves from future hazards of BBIs as well as learn the proper management of exposures. Having good skills while handling sharps injuries, good awareness about the risks, the pre- and postexposure prophylactic measures are important for medical students since they, as future doctors, will be consulted by other categories of HCWs to manage such injuries.

This study was planned to determine the prevalence and correlates of incidences that carry a risk of transmitting a BBI among fourth-year medical students from the University of Colombo, Sri Lanka, which houses the oldest and the largest medical faculty in Sri Lanka with a student population of over 1000 in the academic year 2008/2009. In this study, we also assessed the knowledge, attitudes and practices of pre-exposure precautions and post-exposure practices among these students.

\section{MATERIALS AND METHODS}

A cross-sectional descriptive study of 4th-year medical students was carried out in 2008. These students completed their clinical training and were awaiting the final year attachments in professorial units. They were not given training on the prevention and management of sharps injuries as part of their curriculum. There were 197 students registered in the batch and all the students who were present on the day of data collection (190 students) were included in the study. A total of 168 students consented to participate in the study. The others were requested to leave the lecture hall before the questionnaire was administered. A self-administered questionnaire was used for data collection. This questionnaire contained 114 items in the form of multiple choice questions (MCQs) and short answer questions. It was administered in English which is the language used in teaching and communications in the medical field in Sri Lanka. The questionnaire was pretested using 30 students from a different batch and further changes were made accordingly.

The questionnaire was administered in the students lecture hall after the lectures. The students were explained the purpose of this study and the importance of providing accurate information prior to data collection. They were assured of the confidentiality and were advised to refrain from discussing with one another.

Data entry was done in duplicate by trained research assistants, and the two versions were compared to ensure the accuracy of the data. The data was analyzed using STATA version 11 . The frequencies, percentages and prevalence rate were calculated. Chi-square test was used to assess the significance when relevant.

\section{RESULTS}

The response rate was $88 \%$ with 82 females and 86 males participating in the study. The age of the participants ranged 25-28 years (mean: 26.6 years). All the students 
Table 1. Procedures investigated in this study and the percentages of the students who carried out each procedure

\begin{tabular}{lccr}
\hline & \multicolumn{3}{c}{ Students (\%) } \\
\cline { 2 - 4 } \multicolumn{1}{c}{ Procedure } & $\begin{array}{c}\text { performed } \\
\text { on their } \\
\text { own }\end{array}$ & $\begin{array}{c}\text { assisted } \\
\text { another }\end{array}$ & total* $^{*}$ \\
\hline Venepuncture & 99 & 60 & 100 \\
Femoral venous puncture & 15 & 12 & 18 \\
Arterial puncture (for arterial & 35 & 20 & 43 \\
$\quad$ blood gas assessment) & & & \\
Venous cannulation & 85 & 8 & 92 \\
Suturing wounds & 24 & 40 & 56 \\
Suturing episiotomies & 99 & 100 & 100 \\
Performing vaginal deliveries & 96 & 100 & 100 \\
Wound care/dressing & 48 & 15 & 60 \\
\hline
\end{tabular}

* The percentage of students who either performed or assisted in the procedure.

Table 2. The frequency of injuries according to the procedure that was being carried out at the time of the injury, and the percentages of the students who carried them out

\begin{tabular}{lcc}
\hline \multicolumn{1}{c}{ Procedure } & $\begin{array}{c}\text { Events* } \\
{[\mathrm{n}(\%)]}\end{array}$ & $\begin{array}{c}\text { Students who } \\
\text { experienced } \\
\text { the event** } \\
{[\mathrm{n}(\%)]}\end{array}$ \\
\hline Venepuncture/other needle & $62(17)$ & $42(25)$ \\
Femoral venous puncture & $15(4)$ & $12(7)$ \\
Arterial puncture & $3(1)$ & $3(2)$ \\
Venous cannulation & $24(7)$ & $20(12)$ \\
Suturing wounds & $12(3)$ & $12(7)$ \\
Suturing episiotomies & $172(47)$ & $118(70)$ \\
Performing vaginal deliveries & $36(10)$ & $16(10)$ \\
Assisting in a theater & $8(2)$ & $8(5)$ \\
Wound care/dressing & $13(4)$ & $9(5)$ \\
Other & $23(6)$ & $16(10)$ \\
Total & $368(100)$ & $168(100)$ \\
\hline
\end{tabular}

\footnotetext{
* Including multiple events experienced by the same student.

** The students who experienced one or more accidents that carried a risk of contracting a blood-borne infection.
}

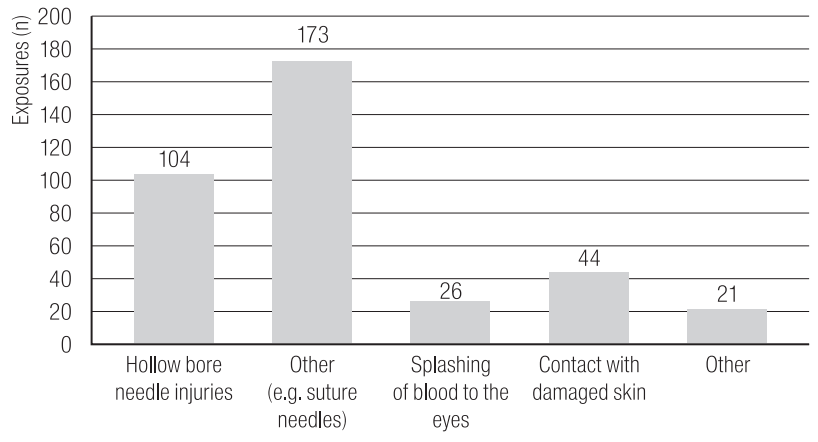

Fig. 1. Types of exposures

completed a minimum of two rotations each in the main specialties that included general surgery, internal medicine, obstetrics, gynecology and pediatrics. During these appointments most of the students carried out one of more invasive procedures considered in the study (Table 1).

One or more events that carried a risk of transmitting a BBI were experienced by $95 \%$ of the students. As many as $89 \%$ of the students experienced one or more sharps injuries. There was no statistically significant difference in facing these high risk events between the males and females (for sustaining one or more injury that was questioned about, $\mathrm{p}=0.14$ ). The students reported the overall number of 368 incidents which they believed to have exposed them to blood-borne infections (Table 2).

Needle-stick injuries accounted for the greatest number of exposures (Figure 1). Another most common exposure was contact of infectious material with mucous membranes and damaged skin. Most of these injuries were sustained while suturing episiotomies which was experienced by $61 \%$ of the students.

\section{Preventive measures}

Pre-exposure prophylaxis

Only $25 \%$ of the students believed that they adhered to universal precautions accurately during their attachments. Only $18 \%$ believed that the staff adhered to universal precautions (UPs). The reasons which the students provided for non-adherence are summarized in Table 3 . The question 
Table 3. Reasons for not following the universal precautions in the wards among the students (themselves) and other staff according to the opinion of the students who participated in this survey

\begin{tabular}{lcc}
\hline \multicolumn{1}{c}{ Reason } & Students (\%) & Other staff $(\%)$ \\
\hline $\begin{array}{l}\text { Lack of awareness of the } \\
\text { universal precautions }\end{array}$ & 15 & 26 \\
$\begin{array}{l}\text { Lack of awareness of the } \\
\text { consequences }\end{array}$ & 30 & 10 \\
$\begin{array}{l}\text { Lack of resources } \\
\text { Lack of anticipation of }\end{array}$ & 42 & 15 \\
$\quad$ accidents & 70 & 30 \\
$\begin{array}{l}\text { Lack of practice in conducting } \\
\text { the procedure }\end{array}$ & 74 & 11 \\
\hline
\end{tabular}

devoted to non-adherence included a section for the students to specify other reasons which they think may lead to the non-observance of universal precautions. A few of the answers to this question were; $12 \%$ - the seniors did not use UPs, therefore the students felt uncomfortable to use them, $8 \%$ - the students were not allowed to use the available protective equipment in the wards, $4 \%$ - a patient might have felt uncomfortable if the UPs were adhered to. The full course of Hepatitis B vaccination was obtained by $154(92 \%)$ of the students, but only $10 \%$ checked their antibody status. All the students (100\%) knew that hepatitis B can be contracted by sharps injuries and other procedures in their clinical training. All the students who did not obtain the vaccine knew that hepatitis $B$ vaccination was available for them and it had been recommended that all medical students should get vaccinated. They all were aware that the immune response is not seen in everyone who completed the vaccination course and the antibody status should be assessed to ensure that they are protected. However, only $15 \%$ knew the place/places where antibody testing was available in Sri Lanka.

\section{Post-exposure practices}

Following the injury, $47 \%$ of the students who sustained an injury completely ignored the event and only 5.7\% of the students followed the accepted post-exposure
Table 4. Causes for not obtaining post-exposure assistance and prophylaxis*

\begin{tabular}{lcc}
\hline \multicolumn{1}{c}{ Post-exposure practice (PEP) } & $\begin{array}{c}\text { Frequency } \\
\text { (n) }\end{array}$ & $\begin{array}{c}\text { Students** } \\
(\%)\end{array}$ \\
\hline $\begin{array}{l}\text { Thought there was no risk - no action } \\
\text { taken }\end{array}$ & 40 & 25.3 \\
$\begin{array}{l}\text { Took a detailed history of the patient } \\
\text { and decided that there was no risk }\end{array}$ & 87 & 55.1 \\
$\begin{array}{l}\text { Told other students - no action } \\
\text { taken }\end{array}$ & 7 & 4.4 \\
$\quad \begin{array}{l}\text { Told the seniors - no action taken } \\
\text { Reported to the infections control unit }\end{array}$ & 10 & 6.3 \\
$\quad$ ICU) - the protocols followed & & 10.1 \\
$\begin{array}{l}\text { Did not know about the ICU } \\
\text { Did not know about the PEP }\end{array}$ & 115 & 72.8 \\
\hline
\end{tabular}

* Students were allowed to choose more than one answer.

** The percentage out of the total number of students $(\mathrm{N}=159)$ who experienced one or more incidents that carried a risk of transmitting a blood-borne infection.

management. The majority (60\%) of the students who ignored the event thought that there was no risk involved. Only 34\% of the students knew about post-exposure management to be applied at the time of the incident. The most common causes for not obtaining the post-exposure assistance are listed in Table 4 . Only $15 \%$ of the subjects reported that their knowledge regarding prevention and management was adequate. The majority (97\%) believed that the curriculum should put more emphasis on improving the knowledge and practice regarding sharps injuries.

\section{DISCUSSION}

Sri Lankan medical students get a broad clinical exposure as part of their clinical training. This is reflected in the number of hands-on procedures they have carried out by the time they reached the 4 th year of their studies. Fourthyear medical students were recruited for this study since they had finished all pre-professorial clinical rotations and were awaiting their final year placements. The injuries 
that took place in the final year of training in professorial units are not included in this study. This study shows a high prevalence of sharps injuries and other accidents that carry a risk of transmitting BBIs among 4th-year medical students at the University of Colombo.

Most of the injuries were sustained during suturing episiotomies. This is a complex procedure and it is one of the procedures that are compulsory for medical students in their training curriculum. As many as $99 \%$ of the students have sutured an episiotomy during their training. These factors may have contributed to the higher prevalence of injuries during suturing episiotomies. Sharps injuries were the commonest injury (277 incidents) and included injuries with both hollow bore needles and solid needles.

Hepatitis B is a vaccine recommended for all health care workers who are at risk of getting the HBV infection [13]. It is available in government hospitals of Sri Lanka and is given free of charge to health care professionals and as part of the immunization program. However, the medical students were not given this free-of-charge vaccine. As this study reveals, although $92 \%$ of the students received the hepatitis B vaccination, only 17 students (10\%) knew their antibody status. The full course of the vaccine is known to cause an antibody response only in $85 \%$ to $90 \%$ [14]. Therefore, approximately 29 students from the survey group may have remained non-immune to Hepatitis B not being aware of this fact. They may also have had a false sense of security since they were vaccinated. This is important since hepatitis B is known to be transmitted by accidental inoculations through abrasions in the skin and mucous membranes even when the victim cannot recall an exposing event [15].

This study showed that most of the surveyed students $(85 \%)$ were aware of the universal precautions. However, the majority of them mentioned that they had not anticipated an accident to take place. This shows the lack of awareness of the students concerning the number of accidents that take place. In addition, $74 \%$ of the students stated that they were not confident while performing the procedure at the time of the accident. The university provides a well-equipped clinical skills laboratory which is freely available for the students to get hands on training before they practiced on patients. The students also had clinical skills sessions that explained the procedures. This study shows that students had not obtained the full use of the skills laboratory. In addition, they were not trained in preventing accidents during these training sessions. That is why it is essential to emphasize the importance of sharps injuries, their high prevalence and the necessity of proper training to avoid injuries. However, the new curriculum addresses this issue by the possibility to take advantage of the skills laboratory and lecture demonstrations for the junior students.

Post-exposure prophylaxis is known to significantly reduce the rate of contracting most infectious diseases including HIV and hepatitis B $[15,16]$. Therefore, following post-exposure management protocols will be useful in reducing the transmission of these infections. This study noted low adherence to post-exposure protocols. Out of those who sustained an injury, $70 \%$ did not obtain professional assistance. Only 16 students (10\%) reported the event to the infectious control unit (ICU) and followed the protocols. Low rates of reporting and adhering to post-exposure guidelines had been reported elsewhere [17]. A similar study in the United States of America among emergency care workers revealed that only $35 \%$ of the subjects reported needle stick injuries. This study demonstrated that under-reporting was highest among physicians when compared to other categories of staff and that their perception of risk is low [18]. Our study shows that the above-mentioned misperceptions and attitudes are seeded during their studentship.

Medical curricula around the world comprise teaching the safety procedures, universal precautions and post-exposure management. However, this training is not alike 
in different regions of the world. The number of injuries and correct post-exposure practices are observed more frequently in centers with extensive training on safety practices. The results of this study emphasize the importance of having a comprehensive pre-clinical training on the safety procedures and post-exposure management of in-ward injuries.

\section{CONCLUSIONS}

This paper presents a hidden problem among medical students in Sri Lanka. High-risk behaviors, a higher number of high-risk injuries and the lack of proper post-exposure practices were noted. The exposures presented above are preventable through proper education, motivation and training. In addition, the students should be encouraged to assess their Hepatitis B immune status following vaccination.

\section{REFERENCES}

1. Prüss-Üstün A, Rapiti E, Hutin YJF. Sharps injuries: global burden of disease from sharps injuries to health-care workers. Geneva: World Health Organization; 2003.

2. Collins CH, Kennedy DA. Microbiological hazards of occupational needlestick and 'sharps' injuries. J Appl Bacteriol 1987;62:385-402.

3. Jagger J. Caring for healthcare workers: a global perspective. Infect Control Hosp Epidemiol 2007;28:1-4.

4. UNAIDS/WHO Working Group on Global HIV/AIDS and STD Surveillance, Joint United Nations Programme on HIV/AIDS, United Nations Children's Fund, World Health Organization. Epidemiological fact sheet on HIV and AIDS: core data on epidemiology and response - Sri Lanka. Geneva, Switzerland: UNAIDS/WHO Working Group on Global HIV/AIDS and STD Surveillance; 2008.

5. Kresge KJ. India revises their HIVIAIDS prevalence estimates. IAVI Rep 2007;11:16.
6. Rodrigo C, Rajapakse S. Current Status of HIVIAIDS in South Asia. J Glob Infect Dis 2009;1:93-101.

7. Abeyewickreme I, de Silva K. Health care systems in transition III. Sri Lanka, Part II. The current status of HIV-AIDS in Sri Lanka. J Public Health Med 2000;22:21-4.

8. Simonsen L, Kane A, Lloyd J, Zaffran M, Kane M. Unsafe injections in the developing world and transmission of bloodborne pathogens: a review. Bull World Health Organ 1999;77: 789-800.

9. Elmiyeh B, Whitaker IS, James MJ, Chahal CA, Galea A, Alshafi K. Needle-stick injuries in the National Health Service: a culture of silence. J R Soc Med 2004;97:326-7.

10. Patterson JM, Novak CB, Mackinnon SE, Ellis RA. Needlestick injuries among medical students. Am J Infect Control 2003;31:226-30.

11. Alamgir H, Cvitkovich Y, Astrakianakis G, Yu S, Yassi A. Needlestick and other potential blood and body fluid exposures among health care workers in British Columbia, Canada. Am J Infect Control 2008;36:12-21.

12. Bowman W, Bohnker BK. Needle-stick epidemiology in Navy health care workers based on INJTRAK reports (2001-2002). Mil Med 2005;170:1034-6.

13. Sagoe-Moses C, Pearson RD, Perry J, Jagger J. Risks to health care workers in developing countries. $\mathrm{N}$ Engl J Med 2001;345:538-41.

14. Salisbury DM, Ramsay M, Noakes K. Immunisation against infectious disease. London: TSO; 2006.

15. Ingerslev J, Mortensen E, Rasmussen K, Jorgensen J, Skinhoj P. Silent hepatitis-B immunization in laboratory technicians. Scand J Clin Lab Invest 1988;48:333-6.

16. Gerberding JL. Management of occupational exposures to blood-borne viruses. N Engl J Med 1995;332:444-51.

17. Patterson JM, Novak CB, Mackinnon SE, Patterson GA. Surgeons' concern and practices of protection against bloodborne pathogens. Ann Surg 1998;228:266-72.

18. Tandberg D, Stewart KK, Doezema D. Under-reporting of contaminated needlestick injuries in emergency health care workers. Ann Emerg Med 1991;20:66-70.

This work is available in Open Access model and licensed under a Creative Commons Attribution-NonCommercial 3.0 Poland License - http://creativecommons.org/ licenses/by-nc/3.0/pl/deed.en. 